\title{
The earliest earwigs in amber (Dermaptera): A new genus and species from the Early Cretaceous of Lebanon
}

\author{
Michael S. Engel ${ }^{a, b, *}$, Jaime Ortega-Blanco ${ }^{c}$ and Dany Azar ${ }^{d}$ \\ ${ }^{a}$ Division of Entomology (Paleoentomology), Natural History Museum, University of Kansas, \\ Lawrence, KS 66049-2811, USA \\ ${ }^{\mathrm{b}}$ Department of Ecology \& Evolutionary Biology, 1501 Crestline Drive, Suite 140, \\ University of Kansas, Lawrence, KS 66049-2811, USA \\ 'Departament d'Estratigrafia, Paleontologia i Geociències Marines, Facultat de Geologia, \\ Universitat de Barcelona, Martí i Franqués s/n, 08028 Barcelona, Spain \\ ${ }^{\mathrm{d}}$ Lebanese University, Faculty of Sciences II, Department of Biology, \\ P.O. Box 26110217, Fanar Matn, Lebanon \\ *Corresponding author, e-mail: msengel@ku.edu \\ Published 1 July 2011
}

\begin{abstract}
Rhadinolabis phoenicica Engel, Ortega-Blanco \& Azar gen. et sp.n. is described and figured from two female earwigs preserved in Early Cretaceous amber from Lebanon, representing the oldest Dermaptera in amber. In addition a partial nymph is recorded from the same deposits. The placement of the genus among Neodermaptera is briefly discussed.
\end{abstract}

\section{Keywords}

Neodermaptera, Mesozoic, Cretaceous

\section{Introduction}

Earwigs (Dermaptera) are one of the smaller orders of insects, with merely around 2000 described species. Nonetheless, the order is morphologically and biologically diverse, and challenging to place among lower Neoptera (e.g., Grimaldi \& Engel 2005; Davis et al. 2010). Earwigs are moderately ancient, with relatively typical-looking species as old as the Late Jurassic, and putative records of earlier forms from as long ago as the Late Triassic (e.g., Jarzembowski 1999; Wappler et al. 2005). Investigation into the amber record of Dermaptera has been only recently initiated, with sundry taxa described from the Early Cretaceous of Myanmar (Cockerell 1920; Engel \& Grimaldi 2004; Engel unpubl. data) and France (Engel 2009; Perrichot et al. in press). The most abundant material are those species preserved in Tertiary resins. Burr (1911) revised the 
middle Eocene Baltic amber species, but his review is now largely of historical value and a new monograph is needed. In addition, a moderately diverse fauna is known from Early Miocene amber of the Dominican Republic and is similarly in need of revision (Engel pers. obs.).

Herein we provide descriptions for new Early Cretaceous earwigs from Lebanon, representing the currently oldest records of Dermaptera in amber. Wappler et al. (2005) provided a catalogue of fossil Dermaptera, updated by Engel (2009), Chatzimanolis and Engel (2010) and Perrichot et al. (in press). The classification scheme of Engel \& Haas (2007) is followed herein and for the discussion. Material discussed herein is temporarily deposited in the Muséum National d'Histoire Naturelle (Paris, France) until such time as a natural history museum is established in Beirut and the material can be repatriated. Specimens were studied and measured (with an ocular micrometer) with an Olympus SZX-12 stereomicroscope, while photomicrographs were prepared using a Nikon D1x digital camera attached to an Infinity K-2 long-distance microscopic lens.

\section{Geological setting}

The fossiliferous amber outcrop of Hammana occurs at a locality named HammanaMdeyrij on the top of the road diverging from the Damascus Road and leading to the village of Hammana. The amber is found in association with lignite and plant debris in dark grey clay and clay-sandstone, in layers belonging to a geological facies considered to be lowermost Aptian in age by Dubertret (1950, 1951). However, this outcrop belongs to the boundary between the top of the Chouf Sandstone Formation and the base of the Abeih Formation, sensu the stratigraphic nomenclature of Walley (1996). The Chouf Sandstone Formation is the "Grés de Base" or C1 of older usage and is the most distinctive unit in Lebanon (Walley 1996). Unfortunately, the age range of the Chouf Sandstone is problematic since it could extend from the terminal Tithonian to Early Aptian, but Shimron \& Lang (1989) have dated the end of the deposition as equivalent to the Kurnub Group and thereby possibly from the Barremian. The lower part of the Abeih Formation may be as old as the Barremian but in general the unit is Early Aptian in age (Walley 1996). The dating of this outcrop was done through palynological studies of the sediments containing the amber (Dejax et al. 1996, 1997). These studies confirmed the Neocomian-Lower Aptian age suggested by Dubertret (1951). Recently, some pollen of angiosperm affinity was found as inclusions in the amber, giving a more precise age of Upper Barremian-Lower Aptian. Curiously, the pollen trapped inside the amber was not represented in the sediment holding the amber. The palynology has shown that the sediments for the Hammana amber deposit correspond to that of a margino-littoral platform, probably related to an estuary, a lagoon, or a deltaic area. Additional discoveries of other amber outcrops in the area and of nearly the same age make the possibility of a delta more probable (Azar et al. 2010). 


\section{Systematic Palaeontology}

Order Dermaptera De Geer, 1773

Suborder Neodermaptera Engel, 2003

\section{Rhadinolabis Engel, Ortega-Blanco \& Azar gen.n.}

Type species

Rhadinolabis phoenicica Engel, Ortega-Blanco \& Azar sp.n.

\section{Diagnosis}

Small earwigs (ca. $3 \mathrm{~mm}$ ); somewhat dorsoventrally compressed, with scattered setae, not chaetulose; integument apparently matt and largely imbricate, without strong sculpturing. Thoracic nota strongly imbricate, with scattered, posteriorly-directed, short, suberect setae; some long, stout, more erect, black setae on apicolateral corners of nota, except apparently with 2-3 such setae on basolateral corners of mesonotum; mesonotum apparently carinate laterally; metanotum apparently ecarinate; tegmina and hind wings apparently completely absent. Metasternum apparently large, broad, quadrate, broadly separating metacoxae, posterior border straight. Legs relatively short; metacoxae apparently widely separated owing to broad metasternum; femora apparently not compressed, not longitudinally carinate, ventral surface not depressed, not greatly elongate; tibiae relatively short, but nonetheless longer than tarsi; tarsi trimerous, second tarsomere greatly shortened, not widened apically, scarcely extending apically beneath third tarsomere (Fig. 5); pretarsal ungues simple, arolium absent. Abdomen parallel-sided, eight visible segments (i.e., female), somewhat dorosoventrally compressed, parallel-sided, apparently about as wide as thorax; abdominal terga sculptured as on thorax, i.e., strongly imbricate, except more apical terga with scattered, shallow, weak punctures on central discs; individual terga slightly broader than long, apical margins straight; apicalmost tergum unmodified (without tubercles or anal process), without mediolongitudinal sulcus, largely covered by penultimate tergum; sterna transverse, apical margins straight; pygidium not completely hidden by terga, basally transverse, with tapering medioapical projection, apex acute and projecting caudad, not deflexed (Fig. 6). Cercal forceps slender, elongate, well separated at base (separated by at least basal width of individual forcep), without dentition or serrations, gradually tapering across length to acute apex, slightly incurved beyond midlength (Figs 1, 2, 4, 6); valvulae not evident.

\section{Etymology}

The new genus-group name is a combination of the Greek terms rhadinos (meaning, "slender, tapering") and labis (meaning, "forceps"). The name is feminine. 
Rhadinolabis phoenicica Engel, Ortega-Blanco \& Azar sp.n. (Figs 1, 2, 4-6)

Diagnosis

As for the genus (vide supra).

\section{Description}

Female. As described for the genus, with the following minor additions and metrics (values for paratype provided in parentheses): Total length as preserved, excluding forceps $3.0 \mathrm{~mm}$; abdominal length $1.63 \mathrm{~mm}(1.0 \mathrm{~mm}$, only apical portion of abdomen preserved), maximum width $0.82 \mathrm{~mm}$ (maximum width of preserved portion $0.68 \mathrm{~mm})$; cercal forceps length $1.10 \mathrm{~mm}(1.12 \mathrm{~mm})$, basal width $0.10 \mathrm{~mm}$ $(0.08 \mathrm{~mm})$, basal separation between forceps $0.13 \mathrm{~mm}(0.12 \mathrm{~mm})$. Integument brown, imbricate; setae generally sparse, simple, short, and lightly fuscous except some slightly longer setae on lateral margins of abdominal segments; cerci generally without setae except a few near base. Lateral abdominal margins relatively straight; terga transverse, wider than long, posterior margins relatively straight; pygidium subtriangular (Fig. 6). Cerci relatively long, longer than one-half abdominal length, tubular and rounded (not trigonal in cross-section), margins smooth, without dentition, crenulations, or serrations.

Male. Unknown.

\section{Holotype}

Female (Fig. 1), largely complete but badly crumpled, particularly head and anterior of thorax; 1013, Azar coll.; Early Cretaceous, Hammana/Mdeyrij, Caza Baabda, Mouhafazit Jabal Loubnan (Mont Lebanon district), Lebanon; provisionally deposited in the Muséum National d'Histoire Naturelle (Paris, France).

\section{Paratype}

Female (Fig. 2), apex of abdomen with forceps and pygidium easily discerned; 1018, Azar coll.; Early Cretaceous, Hammana/Mdeyrij, Caza Baabda, Mouhafazit Jabal Loubnan (Mont Lebanon district), Lebanon; provisionally deposited in the Muséum National d'Histoire Naturelle (Paris, France).

\section{Etymology}

The specific epithet is based on the name of the ancient civilization of Phoenicia (ca. 1200 BC-539 BC) centered in what is today modern-day Lebanon, and extending northward into Syria and south through Israel, and persisting until conquered by Cyrus the Great of Persia. 

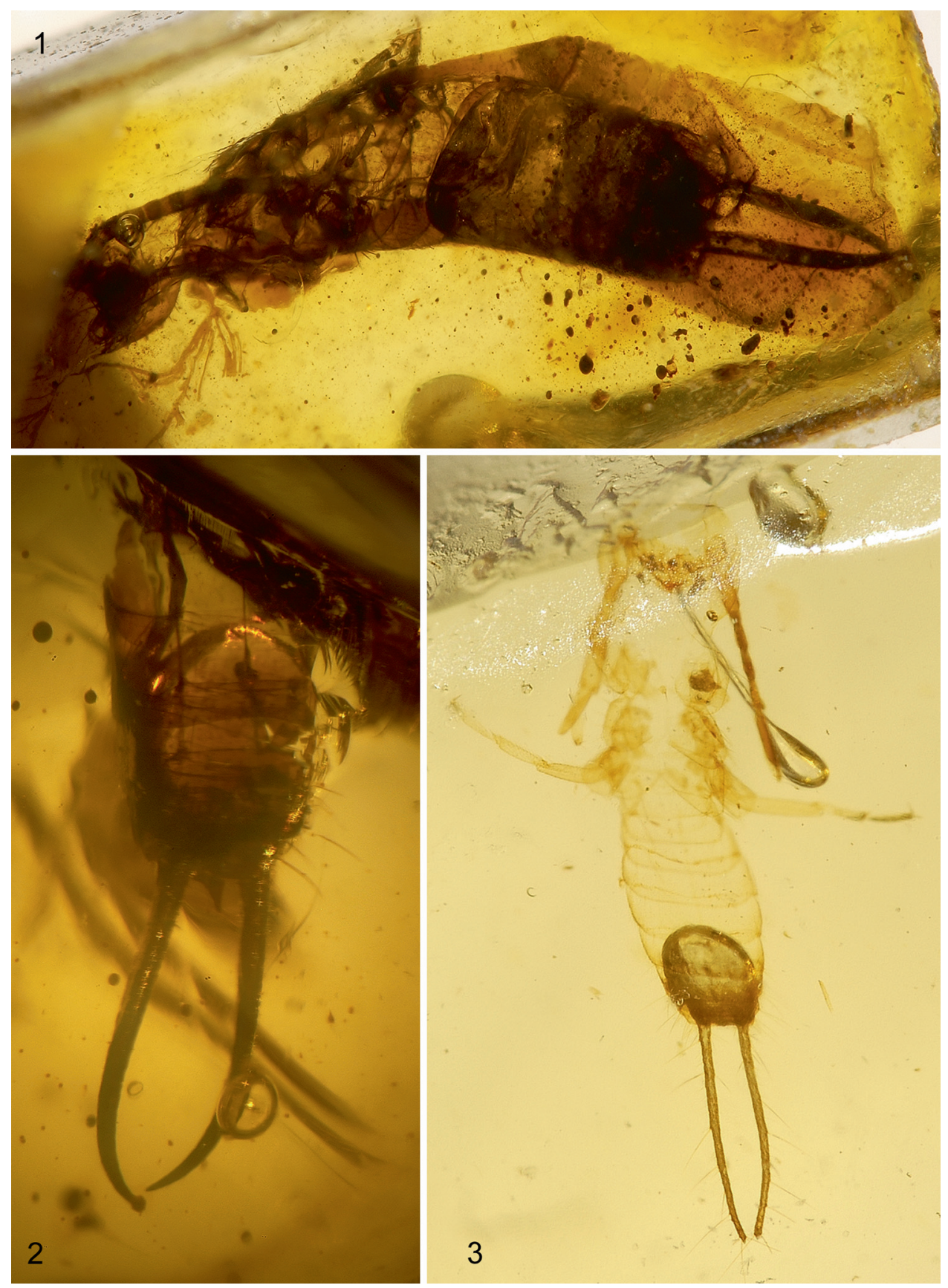

Figs 1-3. Photomicrographs of earwigs in Early Cretaceous amber from Lebanon. (1) Holotype female of Rhadinolabis phoenicica Engel et al. gen. et sp.n. (Azar 1013). (2) Paratype female of R. phoenicica (Azar 1018). (3) Indeterminate nymph (Azar 707). This figure is published in colour in the online version of this journal, which can be accessed via http://www.brill.nl/ise 
Gen. et sp. indet. (nymph) (Figs 3, 7)

\section{Comments}

The available specimen is a shed nymphal exuxium with the following metrics (Fig. 3): total length (as preserved) excluding cerci $1.83 \mathrm{~mm}$; abdominal length $0.88 \mathrm{~mm}$, maximum width $0.48 \mathrm{~mm}$; cercal forceps length $0.83 \mathrm{~mm}$, basal width $0.05 \mathrm{~mm}$, basal separation between forceps $0.08 \mathrm{~mm}$. The integument as preserved is translucent and largely cleared (Fig. 3), with the surface imbricate to smooth and with scattered fine setae, particularly on the abdomen and with those on the cerci noticeably more elongate than those of the body. The specimen preserves few features of taxonomic value, particular given that the head is largely damaged and missing, the antennae are partial, and only some apical podites of the hind legs are preserved (Fig. 7). Fortunately, the metatarsus is well preserved and shows a trimerous arrangement, with the second
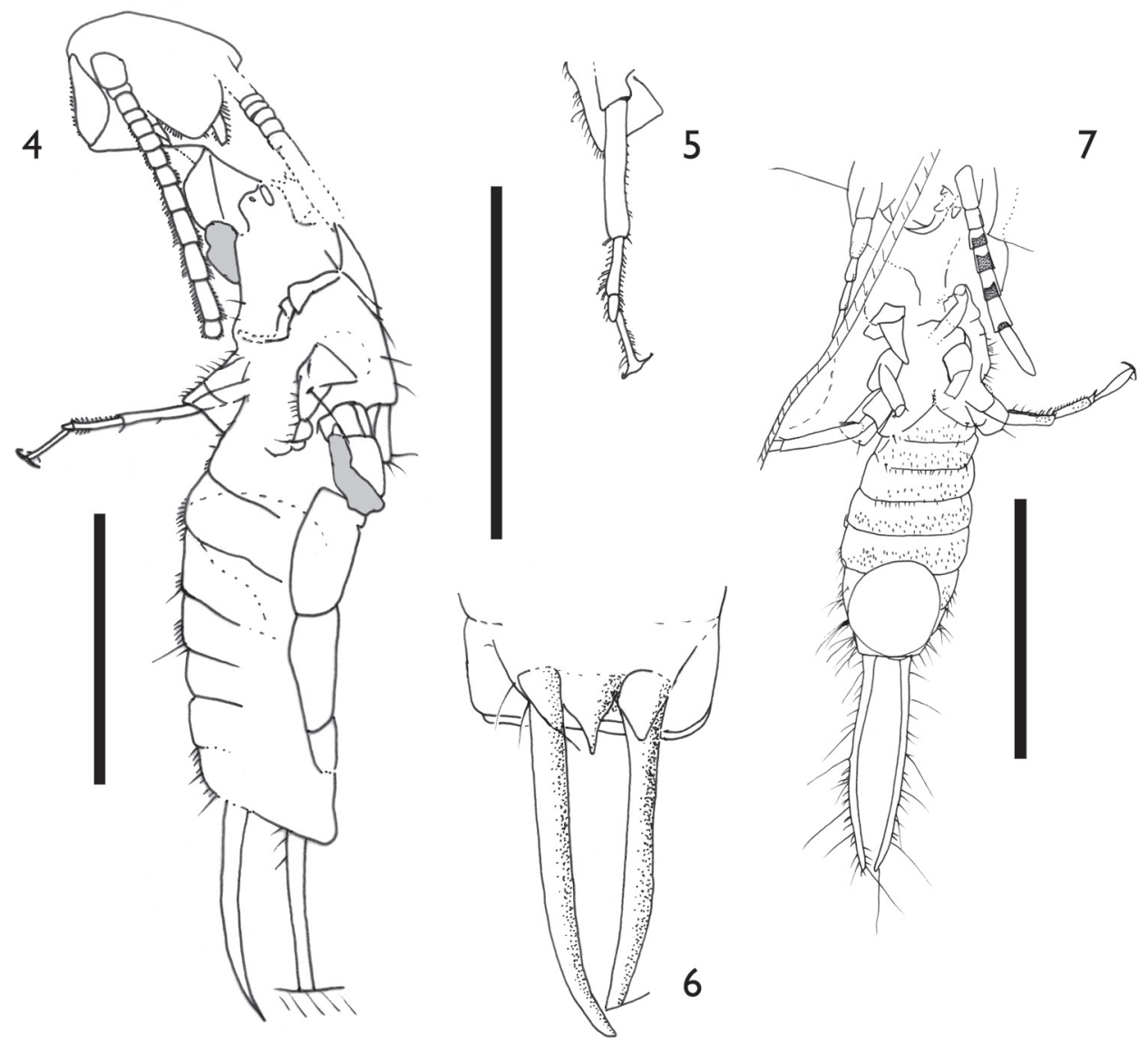

Figs 4-7. Line drawings of Lebanese amber Dermaptera. (4) Holotype female of Rhadinolabis phoenicica Engel et al. gen. et sp.n. (Azar 1013). (5) Detail of holotype leg showing trimerous tarsus. (6) Paratype female of $R$. phoenicica (Azar 1018). (7) Indeterminate nymph (Azar 707). Scale bars=1 mm (Figs 5 and 6 share the same scale bar). 
tarsomere considerably shortened relative to the first and third, but does not project ventrally beneath the third. The pretarsal ungues are simple and no arolium is evident.

\section{Material}

Nymphal exuvium, largely complete with damage to head and legs; 707, Azar coll.; Early Cretaceous, Hammana/Mdeyrij, Caza Baabda, Mouhafazit Jabal Loubnan (Mont Lebanon district), Lebanon; provisionally deposited in the Muséum National d'Histoire Naturelle (Paris, France).

\section{Discussion}

The familial placement of Rhadinolabis is problematic owing to the lack of information for several critical morphological details. The genus can be readily assigned to the Neodermaptera owing to the trimerous tarsi and absence of a well-developed ovipositor, and can be excluded from the Eudermaptera owing to the structure of the tarsi in which the second tarsomere is not greatly expanded, elongate, and projecting strongly beneath the third tarsomere.

The epizoic families Arixeniidae and Hemimeridae can be immediately dismissed owing to the numerous, derived features associated with their parasitic life style. Both arixeniids and hemimerids are generally paedomorphic as adults, and broad, flattened, species, particularly the head and abdomen, with short, stout legs modified for clinging to their hosts, including basal tarsal pads not found in other earwigs (Vosseler 1907; Jordan 1909; Rehn \& Rehn 1935, 1937; Giles 1961, 1963; Popham 1961; Günther \& Herter 1974; Nakata \& Maa 1974; Haas \& Gorb 2004; Beutel \& Gorb 2006). In addition, the cerci of both are thin, elongate and non-annulate, and the antennae short, with comparatively few flagellomeres (Vosseler 1907; Giles 1961, 1963; Popham 1961; Günther \& Herter 1974). Both of these families are likely of Tertiary origin, evolving alongside their mammalian hosts.

The Apachyidae can also be excluded as the tenth abdominal tergum is greatly expanded, with a distinctive broad medial projection between the cercal bases (the "anal process"), the pygidium apparently vestigial; the body, particularly the abdomen, is strongly depressed; the head is distinctly broad, with large and prominent compound eyes; and the pronotum is narrowed anteriorly. No anal process is present in Rhadinolabis and there is a distinct pygidium.

The form of the pygidium is immediately reminiscent of that form typical among the Labiidae, although this shape does occur, albeit far less frequently, in other families and cannot be used for definitive assignment. Moreover, the abbreviated projection of the second tarsomere such that the articulation of the third tarsomere is positioned slightly dorsal on its apical surface is not typical of labiids. Instead, the tarsal structure is more similar to that of labiduroids, but here the pygidium typically is deflexed, such that it is directed ventrally, an attribute not present in the fossil. Indeed, the Anisolabidoidea and Labiduroidea can be dismissed by the distinctly caudad-projecting pygidium in 
Rhadinolabis. Moreover, the slender, tapering forceps are very much unlike the more robust forceps seen in species of these two lineages. The broad, compressed abdomen and shape of the forceps also tends to exclude assignment to the Diplatyidae, and the absence of apparent keels on the femora seems to rule out this family as well as most Pygidicranidae.

Naturally, it is highly probable that Rhadinolabis cannot be assigned to any modern family as currently defined, representing a stem group to one of those lineages or an extinct clade all together independent from any of those evolutionary lines or as an autapomorphic form within some subfamily. For the moment the poor preservation of the available material excludes the possibility of determining which of these scenarios is most supported and thereby which taxonomic decisions should be made regarding its placement within a particular familial group. Nonetheless, the terminalia are quite distinctive and accordingly it should be relatively easy to positively associate more completely preserved, conspecific material, when it is discovered.

The single nymph is similarly challenging to attribute to a particular lineage as the systematics of immature earwigs is in its infancy (e.g., Günther \& Herter 1974; Brindle 1987). The trimerous tarsi places this individual in the Neodermaptera and the nonannulate cerci excludes assignment to the Karschielloidea and Diplatyidae, the only two families in which nymphs primitively retain long, filiform, and multi-annulated cerci in which the basal article alone develops into the adult forceps. It is tantalizing to associate the nymph with Rhadinolabis and, indeed, the tarsal and pretarsal structures are identical between the immature and the holotype of $R$. phoenicica. Unfortunately, no more definitive species-specific attributes can truly link the species and so the present nymph must remain as incertae sedis. Hopefully more complete material of earwigs will be recovered during further investigations of the numerous Lebanese amber deposits.

\section{Acknowledgements}

Partial support was provided by US National Science Foundation grant DEB-0542909 (to M.S.E.). The participation of J.O.-B. was supported by the Ministerio de Ciencia e Innovación of Spain (through project CGL2008-00055/BTE: "The Cretaceous amber of Spain: A pluridisciplinary study", to X. Delclòs). Two anonymous referees are gratefully acknowledged for their comments on the manuscript. This is a contribution of the Division of Entomology, University of Kansas Natural History Museum.

\section{References}

Azar, D., Gèze, R. \& Acra, F. (2010) Lebanese amber. In: Penney, D. (Ed.), Biodiversity of Fossils in Amber from the Major World Deposits. Siri Scientific Press, Manchester, pp. 271-298.

Beutel, R.G. \& Gorb, S.N. (2006) A revised interpretation of the evolution of attachment structures in Hexapoda with special emphasis on Mantophasmatodea. Arthropod Systematics \& Phylogeny 64: $3-25$. 
Brindle, A. (1987) Order Dermaptera. In: Stehr, F.W. (Ed.), Immature Insects, Volume 1. Kendall Hunt Publishing, Dubuque, IA, pp. 171-178.

Burr, M. (1911) Dermaptera (earwigs) preserved in amber from Prussia. Transactions of the Linnean Society of London 2: 145-150.

Chatzimanolis, S. \& Engel, M.S. (2010) Laasbium Scudder: A genus of Tertiary earwigs, not rove beetles, and the classification of Florissant fossil Dermaptera (Insecta). Annales Zoologici 60: 101-108.

Cockerell, T.D.A. (1920) Fossil arthropods in the British Museum - IV. Annals and Magazine of Natural History, Series 9 6: 211-214.

Davis, R.B., Baldauf, S.L. \& Mayhew, P.J. (2010) Many hexapod groups originated earlier and withstood extinction events better than previously realized: Inferences from supertrees. Proceedings of the Royal Society, Series B, Biological Sciences 277: 1597-1606.

Dejax, J., Masure, E. \& Azar, D. (1996) Analyse palynologique d'un échantillon de sédiment du Crétacé inférieur du Liban. Strata 1: 66-67.

Dejax, J., Masure, E. \& Azar, D. (1997) Analyse palynologique de deux échantillons de sédiment du Crétacé inférieur du Liban. XVème Symposium de L'Association des Palynologues de Langue Française, Lyon 1-3 Septembre 1997, pp. 20-21.

Dubertret, L. (1950) Carte Géologique au 1/50 000; Feuille de Djezzine. République Libanaise, Ministère des travaux publics, Beirut.

Dubertret, L. (1951) Carte Géologique au 1/50 000; Feuille de Beyrouth. République Libanaise, Ministère des travaux publics, Beirut.

Engel, M.S. (2009) Gregarious behaviour in Cretaceous earwig nymphs (Insecta, Dermaptera) from southwestern France. Geodiversitas 31: 129-135.

Engel, M.S. \& Grimaldi, D.A. (2004) A primitive earwig in Cretaceous amber from Myanmar (Dermaptera: Pygidicranidae). Journal of Paleontology 78: 1018-1023.

Engel, M.S. \& Haas, F. (2007) Family-group names for earwigs (Dermaptera). American Museum Novitates 3567: 1-20.

Giles, E.T. (1961) Further studies on the growth stages of Arixenia esau Jordan and Arixenia jacobsoni Burr (Dermaptera: Arixeniidae), with a note on the first instar antennae of Hemimerus talpoides Walker (Dermaptera: Hemimeridae). Proceedings of the Royal Entomological Society of London, Series A, General Entomology 36: 21-26.

Giles, E.T. (1963) The comparative external morphology and affinities of the Dermaptera. Transactions of the Royal Entomological Society of London 115: 95-164.

Grimaldi, D. \& Engel, M.S. (2005) Evolution of the Insects. Cambridge University Press, Cambridge, $\mathrm{xv}+755 \mathrm{pp}$.

Günther, K. \& Herter, K. (1974) Dermaptera (Ohrwürmer). Handbuch der Zoologie. [IV.] Band: Arthropoda - 2. Hälfte: Insecta, 2 Teil: Spezielles 11: 1-158.

Haas, F. \& Gorb, S.N. (2004) Evolution of locomotory attachment pads in the Dermaptera (Insecta). Arthropod Structure \& Development 33: 45-66.

Jarzembowski, E.A. (1999) Arthropods 2: Insects. In: Swift, A. \& Martill, D.M. (Eds), Fossils of the Rhaetian Penarth Group. The Palaeontological Association, London, pp. 149-160.

Jordan, K. (1909) Description of a new kind of apterous earwig, apparently parasitic on a bat. Novitates Zoologicae 16: 313-326.

Nakata, S. \& Maa, T.C. (1974) A review of the parasitic earwigs (Dermaptera: Arixeniina; Hemimerina). Pacific Insects 16: 307-374.

Perrichot, V., Engel, M.S., Nel, A., Tafforeau, P. \& Soriano, C. (In press) New earwig nymph (Dermaptera: Pygidicranidae) in mid-Cretaceous amber from France. Cretaceous Research.

Popham, E.J. (1961) On the systematic position of Hemimerus Walker - a case for ordinal status. Proceedings of the Royal Entomological Society of London, Series B: Taxonomy 30: 19-25.

Rehn, J.A.G. \& Rehn, J.W.H. (1935 [1936]) A study of the genus Hemimerus (Dermaptera, Hemimerina, Hemimeridae). Proceedings of the Academy of Natural Sciences 87: 457-508. 
Rehn, J.A.G. \& Rehn, J.W.H. (1937) Further notes on the genus Hemimerus (Dermaptera, Hemimerina, Hemimeridae). Proceedings of the Academy of Natural Sciences 89: 331-335.

Shimron, A.E. \& Lang, B. (1989) Cretaceous magmatism along the southeastern flanc of Mont Hermon. Israel Journal of Earth Science 38: 125-142.

Walley, C.D. 1996. The Stratigraphy and Geological History of Lebanon: An Outline. American University of Beirut, Beirut.

Wappler, T., Engel, M.S. \& Haas, F. (2005) The earwigs (Dermaptera: Forficulidae) from the middle Eocene Eckfeld maar, Germany. Polskie Pismo Entomologiczne 74: 227-250.

Vosseler, J. (1907) Einiges über Hemimerus und sein Wirtstier. Zoologischer Anzeiger 31: 436-450. 